\title{
Pesquisa qualitativa em saúde: reflexões metodológicas do relato oral e produção de narrativas em estudo sobre a profissão médica*
}

\author{
Qualitative research in health studies: methodological reflections on the oral \\ account and narrative technique in a study on the medical profession
}

\author{
Lilia Blima Schraiber \\ Departamento de Medicina Preventina da Faculdade de Medicina da \\ Universidade de Sāo Paulo - Brasil
}

\begin{abstract}
Foi realizada pesquisa qualitativa aplicada à saúde coletiva e medicina social, baseando-se em estudo acerca das transformaçōes históricas da autonomia protisşional dos médicos na passagem da medicina liberal para a atual medicina tecnológica. A pesquisa de campo valeu-5e de entrevistas abertas a gravadas para colher depoimentos pessoais sobre histórias da vida profissional de médicos formados entre 1930-1955. Caracterizados tecnicamente como "relato oral", os depoimentos foram registrados na forma de narrativas livres. Os relatos são considerados quanto à capacidade de expressarem a auto-representaçăo dos médlcos sobre seus cotidianos de trabalho, bem como registrarem a história da prática médica. Avalia-se a entrevista aberta como instrumento de produçáa de narratlvas livies e relatos de vida.
\end{abstract}

Pesquisa, métodos. Prática protissional, historia. Medicina social.

\section{Introdução}

O presente texto traz reflexões de natureza metológica e operacional acerca da pesquisa qualitativa em saúde, tomando por base a investigaçăo realizada em um estudo sobre o médico e seu trabalho ${ }^{22,23}$. Motivado por questōes relativas à organização dos serviços de saúde quanto à inserção dos médicos em açöes integradas com a saúde pública, ou relativas à interdependência das açōes médicas especializadas, o referido estudo constituiu a autonomia profissional desses trabalhadores, seu objeto de investigação.

A medicina foi examinada enquanto trabalho social e os dados empíricos foram extraídos de relatos acerca do trabalho cotidiano. Esses relatos referem-se a momentos históricos de importantes transformações na autonomia dos médicos, equivalendo para a sociedade brasileira aos úitimos 50 anos.

O objetivo do estudo foi o de alcançar informaçōes sobre o trabalho médico no Brasil, não só para obter a história da passagem da medicina liberal para a medicina especializada e "armada" dos dias atuais -à qual se denominou medicina tecnológica-, como também obter as representações dos médicos acerca desse processo e de si mesmos enquanto agentes técnicos e sujeitos históricos.

Do ponto de vista da produçāo dos dados, 0 estudo primeiramente recorreu ao dado já

*Pesquisa subvencionada pela Financiadora de Estudos o Projetos/FINEP (Processo n"4.2.88.0228.00) e Conselho Nacional de Desenvolvimento Cientifico e Tecnologico/CNPq (Processo n ${ }^{\circ}$ 303696/85-MP). Trabalho baseado na Tese de Doutorado do autor - "Medicina liberal e tecnologia: as transformaçōes históricas da autonomia profissional dos médicos em Săo Paulo", apresentada d Faculdade de Medicina da Universidade de São Paulo, 1988. Apresentado ao I Encontro Nacional de Antropologia Médica, Salvador, 3 a 6 de novembro de 1993.

Saparatas/Reprints: Lilia Blima Schraiber - Av. Dr. Arnoldo, 455 - 2*andar - 01246-903 - São Paulo, SP - Brasil

Ediço subvencionada pela FAPESP. Processo 94/0500-0.

Recebido em 13.7.1994. Aprovado em 3.1.1995. 
registrado, valendo-se de três tipos de fontes: textos da história da medicina no Brasil, textos de debate acerca do exercfcio profissional publicados no período histórico em pauta e, por fim, textos biográficos. Essas fontes, contudo, năo foram apropriadas para evidenciar o cotidiano da prática profissional.

Em razão do singular desenvolvimento social brasileiro, no entanto, houve a possibilidade de acesso direto a personagens partícipes do mencionado processo histórico. Isto porque, como mostra o estudo, a transição de um a outro modo de produzir os serviços médicos no Brasil ocupou cerca de 40 a 50 anos, possibilitando que esta passagem fosse vivenciada por poucas gerações de sujeitos, alguns dos quais ainda vivos por ocasião da pesquisa. Assim, a investigação de campo buscou entrevistá-los para a produçăo de narrativas com a qualidade de testemunhos pessoais.

Todos os critérios acima traduziram-se na seleção de médicos cujo início da profissão deu-se entre 1930 e 1955 , buscando-se um resgate das "histórias da vida de trabalho", o que foi orientado por um roteiro de questões muito amplas e um estímulo à livre narração. Os entrevistados foram levados a refletir sobre seu dia-a-dia profissional, trabalhando a "hipótese" central do estudo: a formulação de que a autonomia profissional, perdendo espaço na esfera mercantil, busca centrar-se na dimensāo técnica interna ao processo de trabalho, em um movimento que corresponde à sua tran sformação, para preservar-se enquanto possibilidade objetiva na profissão.

Tratando-se de testemunho acerca de seu próprio trabalbo e estimulando um pensamento sobre questōes tāo caras à medicina, tais como, a tecnologia, a qualidade da intervenção técnica, o papel social da prática médica ou o significado do desenvolvimento científico e profissional, esta produção de narrativas por médicos constituiu rica experiência da perspectiva da pesquisa científica. Não se poderia, por isso mesmo, deixar de refletir a esse respeito.

Assim, tomando-a como ponto de partida, mas também valendo-se de bibliografia específica sobre a pesquisa qualitativa nas Ciências Humanas, desenvolveu-se no presente texto algumas considerações acerca dessa metodologia de pesquisa e da técnica do relato oral por entrevista aberta, tal como utilizadas pelo estudo em questão.

\section{Técnica e Arte do Trabalho de Campo}

\section{Escolhendo Modo e Técnica para a Coleta dos Dados}

Como todo processo de trabalho ${ }^{15}$, a produçāo de dados empíricos na pesquisa também coloca um ardil: encontrar a melhor construção operatória pela qual, a partir das hipóteses científicas, evidenciam-se provas, ou seja, respostas produzidas pelo cientista, com base em métodos, técnicas e instrumentos de investigaçāo. A prova, pois, o cientista capta do real, não só por razões de técnica, mas por ter sido capaz de, ao eleger e exercitar técnicas em seu trabalho de campo, fazer renascer o objeto de seu estudo ${ }^{5}$.

No presente caso, tratava-se de escolher a modalidade de pesquisa capaz de percorrer a dimensåo técnica da prática médica, caminhando pelo interior desse trabalho. Mas, simultaneamente, tratava-se de visualizar, no técnico, a dimensão social. Vale dizer, evidenciar a intervenção médica em sua estruturação técnica, por ser parte da vida em sociedade. Tratavase, ainda, de captar nesse percurso as relações entre o médico e sua prática, permitindo ver na base material desse trabalho a inscriçăo do agente e vice-versa, estudando-se, assim, a dimensão subjetiva das práticas e a concreta constituiçāo dos sujeitos nas açōes.

Por referência à autonomia profissional, a abordagem proposta demandava evindenciá-la como técnica e como representação do traba1ho médico, qualificaçōes em que a autonomia se estabelece, quanto às condiçōes objetivas desse trabalho, como ferramenta adequada e necessária, e, quanto ao imaginário profissional, como ideal de trabalho.

Considerando que se tratava também de um estudo em que todas essas dimensões deveriam expressar-se no movimento histórico da prática médica, dentre as possibilidades de pesquisa qualitativa ${ }^{13,18,21}$, a escolha recaiu sobre a modalidade orientada para produzir relatos em um misto de lembranças das histórias pessoais da vida de trabalho com reflexōes mais gerais sobre o trabalho médico e sobre o movimento de suas transformaç̋̄es.

No pólo empírico da pesquisa, a técnica que lhe foi mais adequada é a da entrevista e, entre seus diversos tipos ${ }^{6.17,19}$, o estudo desenvolveu uma abordagem que estimulasse narrativas mais livres do entrevistado. Impôs-se, 
contudo, limites de temáticas, tentando-se, ao mesmo tempo, garantir que as questões estipuladas pelo roteiro prévio fossem todas recobertas.

Com base na modalidade de relação estabelecida entre o pesquisador e o entrevistado, Queiroz ${ }^{19}$ delimita dois tipos de relatos, considerando a forma mais ou menos espontânea com que o entrevistado produz sua fala. Assim, mesmo no interior das entrevistas mais abertas foram encontradas situações em que é o pesquisador que define os temas e conduz sua abordagem; controla o entrevistado mais prolixo e impõe limites, definindo cortes e a própria conclusão do trabalho. Há, porém, entrevistas em que o tema sugerido é, por si só, ampio, e o entrevistado terá uma narrativa totalmente livre, conduzindo-a a seu ritmo e suficiência. Esta última constitui as histórias de vida, enquan to que a primeira forma, mesmo tratando da experiência vivida, contitui, conforme a autora, os depoimentos pessoais. Esta modalidade é a que melhor expressa a escolha técnica da pesquisa ora examinada.

Mas basear a investigação na produção de um pensamento sobre a experiência vivida significa centrá-la nas representaçóes dos sujeitos, o que, de um lado, constitui a opção de se estudar uma realidade social e coletiva por meio de narrativas individuais e vividos singulares, e de outro, pretender verificar nāo apenas o que esses sujeitos percebem dos diferentes modos de produzir serviços médicos, mas a própria existência objetiva desses modos. Essa metodologia introduz relativamente à aproximação do objeto em estudo, pois, duas ordens articuladas de questōes: o social e o coletivo por referência ao individualsingular que o apreende; e o real objetivo por referência à dimensão subjetiva que o evidencia. Essas são questões que a grande maioria dos textos de referência para esta modalidade de investigação, termina por trabalhar ${ }^{1,2,3,4,9,11,12,19,20}$

A este respeito observou-se, em primeiro lugar, que da perspectiva de se buscar o acontecido através de sua representação no relato individual, esses textos exortam a grande vantagem da técnica de expressar o coletivo, o qual pode-se recuperar nas narrativas obtidas, por meio de uma riqueza ímpar: o coletivo explorado pela reconstrução pessoal. Trata-se da re-produção* do fato social na experiência pessoalmente vivida e na reflexāo que a relata.
É esse processo de re-produção que valida o trabalho com representaçóes e situações singulares para se examinar acontecimentos coletivos e fatos sociais. Sendo cada relato a forma pessoal de expressar o grupo ou o social, o que cada pessoa relata, e o modo como relata, são construções que se determinam na vida em sociedade. Por um lado, sendo construçöes, correspondem a um modo de relatar e, por isso, a entrevista produz sempre uma interpretação daquele que relata, trabalhando na própria subjetividade a objetividade do real. Mas, por outro lado, seu conteúdo, seja relatando o presente ou como recordação, não é exatamente úni$c o$, senão a experiência pessoal no interior de possíveis históricos bem determinados, experiência que dependerá da forma pela qual o narrador posiciona-se socialmente e que lhe produz as concepções acerca do real das quais lançará măo em seu relato ${ }^{14,24}$.

Os médicos entrevistados falam, pois, sobre a medicina liberal, sobre as tensões dessa prática ao crescer o modo tecnológico de produçăa dos serviços e sobre as repercussōes dessas tensões na dimensão técnica do trabalho, mostrando formas historicamente encontradas para a preservação do exercício autônomo. Simultaneamente, expressam concepções acerca do movimento de mudanças que experimentaram. Tudo isso, ao relatarem, porém, o que cada um individualmente viveu.

Em segundo lugar, o que se relata, mesmo sendo pensamento e pensamento individual, não se reduz a uma impressăo subjetiva. É produto de uma elaboração intelectual específica, porque é produto de um pensar que é trabalho, trabalho de refletir e recordar. Por isso não é apenas sentimento, mas a reconstrução do vivido em nova objetivação: toda reflexão é trabalho da memória ${ }^{4}$.

O que foi experimentado no passado e mesmo o que se concebe do presente, ex externado enquanto trabalho de reflexão próptio, distanciando-se dos juízos do senso-comum: o relato é um pensamento especialmente produzido. A entrevista que o suscita deve ser vista como uma experiência particular e não como uma a mais do cotidiano. A entrevista recorta o cotidiano no objeto que propõe à reflexão e o interrompe por meio desta reflexăo, ou como

* O concelto é extraído de H. Lefebvre ${ }^{16}$ e significa: 0 repetitivo que gera diferenças. Daf, inclusive, o modo de grafá-lo (re-prodiuçăo). 
diz Caldeira ${ }^{7}$, a entrevista produz "... uma interpretação que é, em geral, uma ordenação original de coisas velhas, de pedaços de imagens, experiências, opiniōes, etc., que a memória guardou. Esta interpretação (...) é uma visão mais global do que se pode ter no cotidiano".

No presente estudo, também se observam cotidianos e se examina a vida de homenscomuns; mais precisamente, a prática profissional dos médicos-comuns, cujo registro nem sempre ocorre. Esta prática expressa o modo de produzir os serviços médicos nas condiçōes do dia-a-dia, em que o ato médico uniforme e único enquanto modo genérico de medicina, é re-produzido nas desiguais situações de trabatho concretamente existentes na sociedade; reprodução que, na particular situação de trabalho experimentada individualmente pelo médi$c o$, significa reelaboraçăo dos pressupostos e expectativas homogêneas dos médicos, enquanto pensamento coletivo acerca do trabalho médico ideal.

Ao mesmo tempo, o estudo buscou uma recuperaçāo de acontecimentos passados, mas que se faz no presente: o entrevistado não só trabalha a experiência vivida no momento atual, como é levado a recuperar seu passado pelas questōes do presente, questões problematizadas diretamente por ele, assim como pelas problemáticas que o pesquisador lhe coloca.

Por tudo isto o relato sempre será uma lembrança individual, "um ponto de vista sobre a memória coletiva", formas ricas na ampliação, na profundidade e na diferenciação com que se trabalha o coletivo. Mas também, por isso mesmo, cada momento de entrevista e cada relato completado formam subtotalidades que se deve respeitar. A constituição de um todo a partir dos singulares, na reconstituição do acontecimento social, deve considerar que os depoimentos podem se orientar em direçōes diferentes e até contraditórias. Trata-se da autonomia relativa da parte ou do singular; autonomia que, de fato, ocorre, mas não é capaz de anular a inscrição simutânea do coletivo naquilo que é relatado. Esta inscrição poderá ser resgatada desde que se tome o coletivo como tendo qualidade própria por referência a seus constituintes parcelares, o que significa tanto eleger o ponto de vista interpretativo pelo qual se reconstrói a totalidade em estudo, quanto admitir que cada parte individualizada não precisa repetir tudo o que se passa no plano do coletivo para que seja seu efetivo constituinte ${ }^{10,19 *}$.

Por todas essas observações, tal como serão consideradas adiante, a pesquisa exigiu certos cuidados na produção e no processamento intelectua! do material obtido, impondo-se a adoçāo de determinados princípios gerais que orientaram todo o trabalho com o empírico.

\section{Princípios Téenicos e Cotidiano da Pesquisa}

A produçāo das narrativas deve delimitar alguns procedimentos próprios, tais como definir quem, até quando e quantos sujeitos serão entrevitados. Além disso há que se lembrar que a técnica ora discutida produz grande volume de material coletado.

Selecionar sujeitos, no presente caso, levou em consideração alguns pressupostos: inserção na produção de serviços na forma predominante ou exclusiva da medicina de mercado e, pois, médicos-comuns; pertencer ao coletivo de agentes de trabalho "liberal"**, exercendo práticas de intervenção clínica e cirúgica, em suas modalidades mais gerais; e, como critério primeiro dado no recorte inicial do objeto de estudo, praticar a medicina em São Paulo, com a graduação profissional entre 1930-1955.

Essas características indicam qual a posição que os entrevistados ocupam na medicina, đelimitando quais representações e memória grupal inscrevem-se, portanto, nas narrativas.

Também a procura dos sujeitos foi orientada pelo critério de maior facilidade de contacto, no sentido de serem "médicos bastante acessíveis", tendo em vista a dificuldade na obtenção de relatos em investigaçōes dessa natureza, sobretudo considerando a categoria profissional em pauta. Trata-se aqui da pergunta que o entrevistado se coloca e coloca ao pesquisador: "por que $e$ fui o escolhido?". As

\footnotetext{
* A bibliografia pertinente situa no exame interpretativo do material coletado os cuidados relativos à sua aproximnaçăo no sentido de captar o plano do coletivo. A ponta, também, possível suporte nesta tarefa: a complementaçăo das narrativas com outras formas de investigação ou com dados de outra natureza, produzidos em obsrvaçōes diretas ou como material já registrado.

** O termo liberal grafa-se sob aspas pelo fato de que no Brasil esse período, usualmente reconhecido como medicina liberal, năo exibe as mesmas condiçōes de outros países quarto a essá modalidade de trabalho, uma vez que a medicina do pequeno produtor privado e isolado, em boo parte de seu tempo, conviveu com o trabalho assalariado, a medicina dos Institutos ou previdênciárian?
} 
razões da escolha são mais facilmente aceitas quando referidas a situaçōes dos extremos socias: elite e homem-comum do povo. Nelas, por motivos opostos, o entrevistado reconhece a importância de seu relato.

Para o indivíduo que é tido e se vê como representante de grupo, isto é, que adquire uma identidade de elite, a importância de seu depoimento é socialmente difundida e ele próprio a reconhece; para aquele, no extremo oposto, cuja oportunidade da fala constitui rara situação, é o fato de ser entāo valorizado, que conta para sua aceitaçāo em participar da entrevista.

É mais difícil explicitar razōes quando estas não coincidem com nada especial, senão com seu contrário: o grande conjunto de pessoas que constituem grupos quaisquer na sociedade e que podem ser destacadas de seu interior para representar o seu grupo, mas năo exatamente por ser ele indivíduo específico, senão "comum" -um qualquer dentre os do mesmo grupo.

Os médicos, em geral, não são concebidos e não se autoconcebem exatamente na categoria de homens-comuns, mas como grupo muito especial de sujeitos sociais, cujo trabalho, além disso, funda-se na concepção do segredo profissional. Assim, se por um lado, podem entender a necessidade do relato ou a relevância da pesquisa, por outro, detêm a noção de que seus procedimentos, principalmente os da dimensāo técnica, nāo devem ser do conhecimento público. Estâo dispostos, pois, a falar sobre a medicina, talvez até sobre a prática de outros, preferencialmente anônimos... Porém, usualmente, a não ser entre pares (médi$\cos$ ), não falam de si ou de seus cotidianos. Além do que, não tendo sido eleito enquanto sujeito especial, torna-se ainda mais difícil explicar as razōes de sua particular participaçāo.

A seleçăo dos médicos obedeceu, pois, a um princípio especial: não se realizar ao acaso, mas por meio de mecanismos reconhecíveis pelos próprios entrevistados como formas de escolha confiáveis, isto é, formas conhecidas e, de certo ponto de vista, também sob controle deles próprios. Os entrevistados foram, assim, contactados mediante a indicação interpessoal, em que, a partir de médicos próximos e conhecidos do pesquisador, surgiram as primeiras indicaçōes, das quais surgiram novos médicos e assim por diante, o que conformou "geraçōes" de sujeitos indicados.

A menção a cada novo contacto sobre o entrevistado anterior e seu "encaminhamento" permitiu sempre boa recepçāo e disponibilidade do entrevistado para com a pesquisa, reforçando a manutenção desse princípio. Mesmo assim, em 19 contactos, registraram-se 5 recusas.

De todos os médicos que aceitaram participar, a primeira "geração" de indicados (2 médicos) foi objeto de pré-teste ( 16 horas e 30 minutos de gravaçāo) e outros 3 , mesmo constituindo "geraçōes" posteriores, foram abandorados logo após o primeiro contato, em razāo de erro involuntário na indicaçāo. Foram obtidas 9 entrevistas. Gravadas, elas produziram, no total, 38 horas de material registrado.

Esse número de situaçōes seguiu o critério de "exaustāo" ou "saturaçāo", segundo o qual o pesquisador verifica a formação de um todo e reconhece a reconstituição do objeto no conjunto do material. Porém esse não é, de forma alguma, critério obrigatório.

A eleição de critérios que balizam a técnica de coleta dos depoimentos depende do objeto em estudo e do específico campo empírico de investigaçāo. Essa característica de critérios móveis contrasta com outras técnicas de investigaçāo, cujas normas sāo fixas e bem mais independentes por referência aos objetos particulares de estudo. Mas vale aqui lembrar que a adoçāo de critérios implica perspectivas interpretativas do material pertinentes.

Ademais, o rigor nos critérios de seleção dos entrevistados, como também seu número, liga-se a questões de controle sobre dados falsos ou comportamentos "desviantes"13,19. E a situação em que o pesquisador tenta assegurarse de que colherá o dado pertinente e que conseguirá obter a prova que necessita frente a suas hipóteses. Mas nesta modalidade de pesquisa, seja o dado inesperado ou os comportamentos pessoais inesperados ("desviantes"), também podem ser produtivamente explorados. Esse "controle" dá-se no momento "analítico", isto é, inscrevendo no exame do material o inesperado ou destoante. De igual modo, pode ser suficiente apenas um relato de experiência vivida, que convenientemente estudado pode fornecer conhecimentos relevantes acerca da vida social.

Além da saturação, outros critérios foram formulados ao longo do desenvolvimento da investigação, referidos a procedimentos que não podem ser regidos por mecanismos fixos "a priori". O melhor modo de se obter o relato ou quando encerá-lo são problemas que se resolvem 
apenas no desenrolar da narrativa. Isto porque a técnica se funda na exploração de questões que o pesquisador previamente traz, em conjugação com a presença do dado novo, este último criado no momento da entrevista.

Mesmo que o pesquisador já domine questōes da história que indaga e muito embora cada participante já tenha para si uma história guardada, por ocasião da entrevista, como retomada deliberada e provocada dessa história, ela será efetivamente refeita: pelo entrevistado, através de associaçōes, repetiçōes ou desqualificaçós de idéias cujos nexos se constroem no presente da entrevista; pelo pesquisador, na dinâmica do relato - pelos fatos que este traz e em seus encadeamentos, totalmente originais, na narrativa.

Assim, o modo pelo qual o pesquisador pode intervir produtivamente não tem norma fixa e năo se repete de uma a outra entrevista. Não possuindo princípios que de antemão definem o momento e a direçāo da intervençāo, a entrevista conduz sempre a uma atualização do roteiro, fundada na avaliação subjetiva das potencialidades do diálogo.

Eis porque elementos como a simpatia ou, como já se mencionou, o conhecimento prévio dos sujeitos a serem entrevistados, não configuram nessa técnica fator inconveniente. Muito pelo contrário, contituem norma favorável, porque a técnica se fundamenta exatamente na autenticidade e veracidade discursiva do entrevistado, cujo depoimento o pesquisador quer compreender e não contestar ou, mesmo, testar.

$\mathrm{O}$ núcleo do procedimento técnico, neste caso, requer, pois, do entrevistado, o compromisso declarado com suas concep̧̧ỏes e valores, e a disposição moral de evidenciá-los. E do pesquisador, requer a capacidade de estabelecer, com 0 entrevistado, relação pessoal e íntima, para que este se sinta à vontade no relato ${ }^{4,20,21}$.

Assim, o "controle" sobre a investigação, que se dá mais no sentido de garantir a presença das questões que a pesquisa coloca, frequientemente se faz com base em critérios criados no momento da entrevista. Eis porque o diálogo estabelecido na relação pesquisador entrevistado deve ser adequadamente articulado ao próprio objeto de estudo, residindo o "controle" do processo da entrevista sobretudo neste domínio intelectual do pesquisador. Por isso, também, de forma bastante flexível, quer o roteiro, quer a intervenção do pesquisador, são ferramentas importantes no processo da entrevista, mas que apenas ganham sentido no momento concreto do relato em produçāo.

O roteiro, em particular, assume o papel de guia da narrativa e é utilizado para orientar o pesquisador na colocação de temas estimulantes do relato, constituindo apoio ao trabalho da reflexão ou memória auxiliar. Deve-se percorrêlo subordinadamente à dinâmica que o próprio entrevistado da à narrativa e respeitando a seqüência das questōes que o relato produz. Algumas temáticas surgem como questões já problematizadas e certas informaçöes aparecem relatadas espontaneamente, sugerindo questões relevantes para o narrador e como expressāo também da membria grupal. Outras têm que ser sistematicamente estimuladas pelo pesquisador.

Entre as primeiras, no presente estudo observam-se, por exemplo, a perda da autonomia mercantil $e$ o assalariamento do médico, ou rotina e a impessoalidade da prática, decorrentes da massificação e institucionalização da medicina. Mas, a mais significativa questão foi, sem dúvida, o Estado como grande produtor, interferindo diretamente na dinâmica mercantil, o que é trabalhado, via de regra, sob a forma de protesto contra a política pública para o setor. Como ilustração do segundo conjunto de informaçōes, foram observadas as questōes referentes à autonomia técnica e ligadas à intimidade do processo de intervenção, dimensāo sempre muito preservada de reflexão e, sobretudo, de indagaçōes. Assim, a especialização ou a inovaçāo tecnologica concreta são aspectos que, quando referidos, são colocados como atributos "naturais" da medicina, parecendo quase não necessitar de "reflexăo".

O relato mais espontâneo parece reservado para aspectos tidos como "genéricos" da profissāo: os outros; o saber científico; o desenvolvimento tecnológico em abstrato. $\mathrm{Ou}$, aspectos "externos": o governo; as instituiçóes; a crise econômica do país. Reserva-se, ainda, do ponto de vista da história, para o que se crê "perdido": o lado negativo da mudança, isto é, o que deixa de ser valorizado, segundo o imaginário profissional.

Raramente, ao contrário, os entrevistados supuseram a necessidade de contar ou de valerse de uma fala mais densa que a mera constataçāo, para os aspectos opostos aos anteriores: $o$ caso profissional particular, com suas mazelas e dificuldades do dia-a-dia; o relato do interior da prática, em que se evidencia a abordagem do 
doente para sua assistência e a formulaçäo do julgamento ou decisão médica; ou, diante do desenrolar histórico, as mudanças "positivas", como a incorporação dos equipamentos ou a "cientificidade" "aumentada" da prática ma. terialmente armada.

Alguma reflexão mais crítica, portanto, parece importar apenas para as "perdas" históricas ou as adversidades, do passado ou do presente, quase nunca articulando, em um mesmo pensamento crítico, a totalidade dos aspectos e qualificações do exercício profissional.

Este último posicionamento, inclusive, os faz mudar, no tempo, a "fronteira" do que lhes pertence, o que nos é evidenciado por mudan. ças do alvo merecedor de reflexảo crítica e, pois, objeto da narrativa mais espontânea, à proporção que o relato percorre diferentes momentos da historia pessoal recordada. É o que ocorre, por exemplo, quando falam de sua participaçảo pessoal na construçāo de suas condições de trabalho relativamente à prática liberal, quando os mecanismos sociais conformadores da produção na modalidade consultório privado não são reconhecidos enquanto forma social e estruturada de autonomia técnica e mercantil, parecendo-lhes sempre algo seu: esforço pessoal, vocação individual e reta conduta moral na profissão. Ao passo que, na medicina tecnológica, o compromisso pessoal para com as condições de trabalho (quaisquer delas), apontado no momento anterior, é o que deixa de ser reconhecido, por nāo mais se incluir, mesmo enquanto produçāo de setor privado, como algo "interno" à fronteira técnico-profíssional, repercutindo diretamente no conceito de autonomia e em seus pólos: liberdade e responsabilidade.

Nos relatos, essa forma distinta de tratamento das questões (do superficial ao pensamento crítico mais articulado), indica-nos a importância que cada conjunto de temas adquire para o entrevistado. E a observaçāo deste aspecto, expressivo quanto às concepçöes acerca da medicina como trabalho social e quanto à auto-representaçāo, tornou-se possível em razão do temário previsto pelo roteiro. Este percorria não só a vida de trabalho, mas a vida em família, no lazer e na escolarização. Ademais, percorria a vida experimentada nos vários momentos decorridos desde a infância, por onde, inclusive, se iniciou a entrevista. No plano da vida de trabalho, o roteiro estimulava a descri- ção detalhada dos vários aspectos envolvendo a estruturação da prática profissional, a qual foi tomada desde o seu início, mantendo-se essa descrição mais "densa" como eixo de aproximaçăo do transcurso da prática até momentos recentes, destacando-se em especial a reflexão relativa ao trabalho do consultório privado.

Buscando verificar, justamente, a estruturação dos exercícios profissionais concretos e particulares diante dos modos vigentes de produção de serviços médicos na sociedade brasileira, observando, inclusive, de que forma essas estruturações "acompanharam" as transformações históricas dessa sociedade, e, principalmente, tentando verificar a posiçăo do médico em sua prática, o roteiro conduzia a temas como: a finalidade do trabalho profissional; os instrumentos e equipamentos, além de técnicas de intervenção utilizadas; as relaçōes de cada trabalho com outros serviços médicos; cada clientela e seus doentes como objeto da intervençăo; e, essencialmente, atos concretos de realizaçăo do cuidado médico, como processo, isto é, a atividade do trabalho. Para facilitar o relato acerca desse último aspecto, estimulouse a descrição de situaçỏes marcantes no exercício profissional vivido, incentivando os casos e os exemplos, ainda que a narrativa mais livre logo conduza a fala para essa direçăo.

Da mesma forma que o uso do roteiro, delimitar o tempo de duraçåo e o momento de encerrar a entrevista foi algo estabelecido no transcorrer do trabalho de campo. De um modo geral o tempo é longo, mas näo se pode fixá-lo previamente, além do que varia para cada situaçāo. Da perspectiva do encerramento da entrevista, o cumprimento dos itens do roteiro, como conteúdo mínimo da reflexão prosposta, pode ser um born ponto de partida, porém, de modo algum indica o término do trabalho de produção das narrativas. Como trabalho de reflexão, sua conclusão está dada pela suficiência de tratamento dos temas e quando estes se esgotam como forma de alimentar o diálogo, o que novamente se pode demarcar apenas no interior da dinâmica dos relatos.

Esse conjunto de envolvimentos do pesquisador com o objeto que investiga confere uma qualidade muito viva ao processo, em um caráter de permanente construçāo de modelo operatório da própria investigação, o que traz ao pesquisador quase sempre muitas dúvidas. Desse ponto de vista alguns procedimentos 
complementares à entrevista podem orientar melhor o processo, como é o caso dos sempre referidos, nessa modalidade de pesquisa, " $c a$ dernos de campo" em que são anotadas as próprias percepções do pesquisador acerca da investigação em curso.

Não obstante, é o conhecimento do objeto de estudo e das questões que foram selecionadas para trabalhá-lo que muito auxiliam nos jugamentos e decisões, exigindo do pesquisador domínio sobre a pesquisa tal que torne seus procedimentos uma forma viva de exercício de subjetividade tcoricamente fundamentada, isto é, o próprio pesquisador como instrumento de investigação e não apenas em mero portador de impressōes pessoais. Além disso e nesse mesmo sentido, sem prentender que todos os procedimentos adotados tornem-se regras universais, para que 0 processo não resulte em uma ação subjetiva pessoal, deve-se estabelecer princípios que presidam a intencionalidade da ação técnica na pesquisa, ainda que a estratégia de conduzi-los dependa fundamentalmente de cada relação interindividual que se consegue estabelecer.

Embora alguns princípios já tenham sido mencionados, eles podem ser assim sintetizados. Um primeiro princípio tomou a entrevista como meio de conhecimento, conforme já sc considerou no presente texto. Fundou-se, portanto, a ação do investigador no fato de que não sc tratava de uma polêmica, um embate polítjco-ideológico, nem um teste de conhecimentos ou objetivaçōes neutras de "verdade absoluta". O fundamento residiu na necessidade de encontrar formas de apreender, com clareza, as representações próprias do entrevistado e o diálogo transcorreu sempre no sentido de recordação dos fatos e esclarecimentos dos valores, incentivando o trabalho de reflexão em ambos os sentidos. A intervenção do pesquisador se pautou $\mathrm{cm}$ falas bastante explícitas para que se pudesse questionar o entrevistado o mais abertamente possível, mesmo que, dada a busca de produzir narrativas livres, tanto se a reduziu ao indispensável, quanto se lançou mão do roteiro apenas quando suas questões não cram trabalhadas espontaneamente, o que foi feito sempre com sugestão de temas em sua forma mais geral.

Não obstante, ocorreram alguns impasses de conversação. Foram situaçōes em que, mesmo involuntariamente, a sugestão foi formulada de modo inadequado, o que ocorreu seja porque, para o pesquisador, de fato eram diver- sas as concepções e as problemáticas que valorizou, por referência às do entrevistado, seja porque as questóes trazidas remetiam a um vivido pessoal (do pesquisador) referido a uma época histórica muito diversa daquela em que o entrevistado vivenciou a maior parte de suas experiências profissionais. O pesquisador, portanto, terminou por produzir algumas falas distantes do entrevistado, em uma linguagem que, a este, foi, muitas vezes, estranha.

O processo da entrevista, desse ângulo, representou processo de aprendizado para o pesquisador, no sentido de encontrar modos adequados de participar, até certo ponto, das mesmas concepções e da mesma forma de pensar a realidade que o entrevistado possui, sobre o presente e sobre o passado. A entrevista, assim, não é só uma forma de entender e captar o outro, mas de se fazer entender, e tanto a história de vida como a posição social e científica distinta do pesquisador relativamente ao entrevistado, introduzem linguagens divergentes.

Em parte decorente do mesmo princípio anterior e em parte com base nestas últimas observações, houve a necessidade de se fazer um "contrato" de trabalho bastante preciso, esclarecendo o mais possível o objeto co recorte temático escolhidos para a pesquisa; as razões, os sentidos e as pretensōes da pesquisa; $c$ a forma indicativa de organizar o trabalho de investigação: como, quando e onde se fariam as entrevistas, bem como a duração presumível de cada sessão ou do número de sessões desejável. Também o pesquisador deve colocar-se autêntico e veraz na relaçāo com o entrevistado.

Da perspectiva dessa organização do trabalho de campo, as explicitações foram no sentido de que iria tratar-se de um trabalho relativamente prolongado, com o uso de gravador, com sessões de gravação não muito curtas e sobretudo por meio de sessóes repetidas, critérios fixados com base na experiência das primeiras entrevistas. Essa explicitação das "regras do jogo" foi de grande importância, pois é frequiente o indivíduo contactado pensar que se trata de pesquisa de curta duração ou com questinários padronizados, e a ocorrência oposta, por fugir ao esperado, parece requerer explicações mais detalhadas.

O trabalho de campo ocupou cerca de quatro e meia sessões de gravação por entrevistado, variando de três até nove para um mesmo sujeito, em razão da disponibilidade e prolixi- 
dade de cada narrador. A duraçāo que se conseguiu obter em cada uma das sessões de grava̧̧ão marcou um tempo que quase sempre se pautou no próprio cansaço do entrevistado, fruto do trabalho de reflexão e de narrar, ocupando mais frequientamente uma hora de gravação, sendo o máximo atingido o de duas horas de gravaçāo, em uma mesma sessão.

Repartir a narrativa por várias sessões de gravaçāo mostrou-se produtivo sob dois pontos de vista. Primeiro porque, para o próprio trabalho de refletir e lembrar, o intervalo decorrido de uma a outra sessāo produziu efeitos relevantes, verificado no fato de que quase sempre ao início de cada sessão, mesmo que parecesse já trabalhado determinado tema na etapa anterior, o entrevistado espontaneamente solicitava o registro de outros novos aspectos lembrados, por ter prosseguido em sua reflexão após o registro anterior. Em segundo lugar, esse intervalo permitiu combinar, ao uso do caderno de campo, o estudo sistemático do segmento discursivo já grava. do. $E$ assim foi feito, precedendo cada nova sessāo, o que permititu explorar com mais segurança as narrativas, à medida que se vinham produzindo.

$O$ conjunto desses critérios fez com que se evitasse entrevistar mais que dois sujeitos, na mesma etapa do trabalho de campo, o que, somado ao tempo gasto com localização, contactos e efetivação da entrevista, produziu uma duraçāo global de 6 meses para este trabalho, parâmetro a ser considerado também na delimi. taçāo da quantidade de relatos a serem produzidos e no dimensionamento da investigaçāo empírica.

Na produção das informações, combinouse o uso sistemático e articulado de dois instrumentos de registro, os quais, como já dito, foram; o gravador e o caderno de campo. Este último serviu para anotar diversos tipos de dados, operação feita sempre ao final de cada sessão, identificando-a no caderno. Foram anotações referidas à própria experiência vivenciada na entrevista, através da efetivação de suas técnicas de abordagem e obtençāo dos relatos, avaliando-as no sentido de sua eficácia, produtividade e impasses para a investigação. Também se registraram informaçōes sobre o entrevistado, seu comportamento geral na entrevista e em particular quanto aos temas e à dinâmica com que transcorriam. Foram valiosas as ano- tações feitas acerca do local de trabalho, quando as entrevistas realizaram-se no consultório particular (o que ocorreu em 6 dos 9 casos).

Em muitas ocasiões registraram-se informações que o próprio entrevistado fornecia fora da gravação, as quais não foram poucas ou irrelevantes. Pode-se mesmo dizer que uma outra entrevista se passa nos intervalos, na "hora do cafezinho", ou ao término da sessão, após concluída a gravação. As falas nesses momentos são descontraídas e recobrem assuntos de todos os tipos: o entrevistado opina sobre a entrevista, sobre os médicos, sobre a medicina, sobre sua vida e se inteira da vida do pesquisador, comenta a técnica, a possível participação de outros colegas, e assim por diante. São extremamente valiosas, pois, esssas anotações.

De outro lado, esses momentos informais de aproximação são vitais para a própria realizaçăo da investigação, uma vez que determinam as bases da relação interpessoal, com a formaçăo de vínculos que uItrapassam o formal, criando-se laços de amizade, simpatia e confiança, pelo mútuo interesse que se estabelece - e há que se dar de fato - pela pessoa que ali está. A transformação do narrador em objeto de pesquisa morto e paralisado retira qualquer possibilidade de serem criadas relaçōes efetivatnente capazes de dar conta de um trabatho de investigaçāo dessa espécie. Além disso, essa postura nāo significa, para qualquer dos dois sujeitos, esforço negativo: ao contrário, expressa a cumplicidade do mútuo empenho para se produzir o relato e para se conservar, no tempo, o depoimento e a historia ${ }^{4,4}$.

Quanto ao uso do gravador, este instrumento, de fato, "representa uma ampliaçāo do poder de registro" 20 , pela produtividade maior da operação e pelo registro de viva voz. Permite captar e reter por maior tempo um conjunto amplo de elementos de comunicação de extrema importância: as pausas de refiexão e de dúvida ou a entonaçăo da voz nas expressões de surpresa, entusiasmo, crítica, ceticismo, ou erros - elementos esses que compõem com as idéias e os conceitos a produção do sentido da fala, aprimorando a compreensão da própria narrativa.

Mas gravar implica um trabalho dispendioso e difícil de transcriçāo de todo o material obtido. Trabalho que, se é possível fazer realizar-se à medida que sāo produzidas as narrativas, economizando tempo de processamento de dados, requer razoáveis parcelas de recursos 
financeiros, alem de demandar conferência da própria qualidade da transcrição. É, porém, etapa obrigatória, já que facilita o manuseio posterior dos registros e, por ser a fita material perecível, termina-se perdendo o registro como documento de arquivo.

O uso do gravador introduz, de outro lado, pela presença da própria máquina (o "terceiro" participante), a consciência de que of fiel retrato da narrativa e na forma exata de sua enunciaçảo, está se tornando público, por vezes inibindo o relato ou trazendo a excessiva preocupaçăo com desempenho pessoal.

Mas a necessidade da transcriçåo ou a presença desse "outro" na entrevista são apenas pequenos problemas, pouco alterando as vantagens da gravação como forma de registro.

Após a gravação, um primeiro trabalho com o material, o da transcriçẫo, representa a passagem da forma oral para a linguagem escrita, de modo fiel ao contido na gravação. Isto exige tanto selecionar um adequado profissional, quanto o acompanhamento da atividade, este último, aspecto importante, já que o profissional da transcriçåo raramente domina o linguajar próprio de segmentos técnicos determinados, ou..."a língua dos médicos", assim como há o "sociologuês", o "economês", e outros... Para se ter uma idéia do tipo de trabalho que envolve, vale destacar que cada hora gravada produziu, em média, 30 laudas datilografadas, em espaço de aproveitamento máximo da lauda, o que produziu um volume total de 1.142 páginas de material coletado.

Um segundo trabalho com o material, o de edição, significa definir critérios de editoria e forma de publicação, o que no presente caso seguiu criterios de "anonimato" dos informantes, maior concisão e continuidade nas narrativas e individualizaçāo dos relatos, excluindose, no texto final, as intervençōes do pesquisador e optando-se pela ordenação temporal das histórias, iniciando-se com o depoimento do médico mais antigo na profissāo e concluindose com o mais jovem ${ }^{22}$.

Um último trabalho realizado foi o exame totalizador a leitura trans-individual dos relatos. Nesse sentido, há que se mencionar o duplo caráter desse material: ao mesmo tempo dado empírico para a exploração de dimensōes transcendentes ao singular, tanto quanto já resultado do estudo. Como resultado é produto de trabalho específico no interior da investiga- ção de campo, trabalho em que se produz uma forma própria de objetivação dos temas selecionados: objetivaçåo cientificamente fundada, diferenciando-se de outros discursos acerca do real. Desta perspectiva as narrativas prescindiriam deste terceiro momento de trabalho.

Mas optando-se, no presente estudo, por interpretá-las para produzir outros mais resultados, as narrativas foram lidas como historias particulares de modelos genéricos de profissāo e que contam as várias estruturaçōes concretas do exercício profissional, cujos perfis individuais estarão, em alguns casos mais e noutros menos, próximos da condição tecnológica geral do modo de produção de serviços em que se inscrevem. Da perspectiva totalizadora, então, o leque de estruturações registrado foi abordado como um conjunto, sem deixar de levar em conta a singularidade de cada historia produzida. Para tanto, é preciso, primeiro, dominar o todo de uma mesma história, para poder confrontá-lo com outra. Impregnarse de cada todo, é o termo que a literatura específica consagra a este proceder ${ }^{20}$. $O$ destaque a fragmentos, que aparece na abordagem de conjunto e, portanto, comparativa dos relatos singulares, pressupõe que se tenha apreendido o sentido próprio do fragmento na totalidade do pensamento do qual é separado, tal como buscou-se realizar.

Como as narrativas, além de ferramentas de aproximação das representações, foram também tomadas como instrumentos de observação da prática, sem desconhecer a ocorrência de falas mais descritivas ou mais opinativas, foi o todo do discurso conformado que se examinou. A leitura das narrativas se fez, portanto, não só quanto às representações, mas igualmente através das representações, para alcançar os procedimentos concretos pelos quais se organizaram e se transformaram os exercícios profissionais. Assim, o modo específico pelo qual foram trabalhadas as idéias, as noçōes e as concepçōes do pensamento médico supôs considerá-las como constituintes da prática do médico, articuladas ao exercício profissional que dotam de significaçåo. Podem, assim, relatálo, situando nele o agente técnico e sujeito histórico; ao mesmo tempo que sendo processo de significaçāo, representam a construçāo de pensamento acerca do trabalho e sua história. A realização do trabalho analítico com o material buscou alcançar todos estes sentidos. 


\section{Considerações Finais}

À guisa de conclusão das presentes reflexōes, seria importante algumas observações, ressaltando o que se considera contribuições do presente estudo acerca do trabalho médico, com base na metodologia da pesquisa qualitativa e na específica técnica ora examinada.

O caráter do instrumento de pesquisa muito amplo, sua definição sob princípios operativos muito genéricos e a grande dose de decisões pessoais do pesquisador no curso de sua utilizaçāo no trabalho de campo, têm sido os aspectos mais polêmicos quanto à tecnicalidade desta forma de investigaçăo. São eles, porém, ao mesmo tempo, sua marca mais produtiva. É exatamente esta sua natureza que permite meIhor explorar a subjetividade como objeto de conhecimento, já que promove resgate das dimensōes sujetivas dos processos sociais que respeita o todo complexo de sua constituição. Tal capacidade nos é evidenciada por ser o relato oral a apreensão da subjetividade na forma de um pensamento externalizado, vale dizer, a narrativa. Trata-se, assim, da objetivação de pensamentos, por meio da construção de um pensar.

Por isso, credita-se à pesquisa qualitativa e particularmente à produção de narrativas, a característica de ferramenta extremamente apropriada para o estudo das as representações. No presente caso, o estudo desdobrou-se em representaçōes acerca da realidade objetiva da prática médica e em auto-representações, permitindo

\section{Referências Bibliográticas}

1. BALAN, J.\& JELIN, E. Lastructure sociale dans labiographie personnelle. Cah. Int. Sociol., 69:269-89, 1980.

2. BERTAUX, D. Biography and saciety: the life-history approach in the social sciences. New York, Sage, 1981.

3. BERTAUX, D. L'approche biographique: sa validité méthodologique, ses potencialités. Cah. Int. Sociol. $69: 197-225,1980$.

4. BOSI, E. Memória e sociedade: tembranças de velhos. São Paulo, T. A. Queiroz, 1983.

5. BRUYNE, P. de; HERMAN, J.; SCHOUTHEETE, M. Dinämica da pesquisa em ciências suciais. 2a. ed. Rio de Janeiro, Livraria Francisco Alves Ed. S. A., 1977.

6. BURGESS, R. G. Field research: a sourcebook and field mantat. London, George Allen and Unwin, 1982.

7. CALDEIRA, T. P. do R. A política dos outros: o cotidiano dos moradores da periferia e o que pensam do poder $e$ dos poderosos. São Paulo, Brasiliense, 1984.

8. CALDEjRA, T. P. do R. Uma incursăo pelo lado "năo respeitável" da pesquisa de campo. Ciênc. Soc. Hoje (1): $332-54,1981$ explorar de duplo modo a dimensão subjetiva do trabalho médico.

Da perspectiva de estudo histórico, esta forma de investigação empírica possibilitou, de fato, inscrever a cotidianidade na dinâmica de mudanças observadas, ao longo do período de tempo considerado. E esta possibilidade é especialmente importante no caso da história da medicina, em razão dos mencionados desvios de registro histórico, que valorizam quer os feitos pessoais, quer os fatos científicotecnológicos, enquanto a natureza própria da memória neste campo.

Já enquanto estudo da prática médica como trabalho social, ao resgatar um modelo de trabalho, o pensamento médico acerca desse modelo e a auto-representação de seus partícipes, o relato oral expôs as percepções acerca do cotidiano articuladamente à reconstituição objetiva deste. Permitiu-se, assim, não só conhecer o pensamento de personagens técnicos acerca de processos sociais, mas revelar alguns aspectos éticos e lógicos de sua forma de pensar: a produção de narrativas mais livres, reconstituindo esse pensamento, fez emergir o valorizado e o desqualificado, bem como o problemático e o natural, para as percepções singulares e para seu conjunto, o pensamento médico. Sua leitura, então, possível, nos fará compreender a cultura profissional, as imagens idealizadas acerca da prática e como se autoconcebem, na história e na sociedade, estes cujas práticas técnicas os situam enquanto privilegiados atores sociais.

9. CAMARGO, A. A. Os usos du história oral e da história de vida: trabalhando com elites políticas. DADOS-Rev. Ciênc. Soc, 27:5-28, 1984.

10. CAMARGO, A. A. O ator, o pesquisador e a história: impasses metodológicos na lmplantação do Centro de Pesquisa e Documentação de História Contemporânea do Brasil, In: Nunes, E. de O. org. A aventura sociológicus objetividade, paixāo, improviso e métsdo napesquisa social. Rio de Janeiro, ZanharEd., 1978.p. 276-304.

11. CAMARGO, A. A.; HIPPOLITO, L.; ROCHA-LIMA., V. da. História de vida na América Latina. BlBI, 16:5-24, 1983.

I2. DURHAM, E. R. Cultura e ideologia. DADOS-Rev. Ciênc: Soc. 27:71-89, 1984 .

13. FERNANDES, F, Ensaios de sociologia geral e aplicada. Sảo Paulo. 2a. ed. Pioneira, 1971.

14. FERRAROTI, F. Les biographies comme instrument analytique et interprétatif. Cah. Int. Soćiol, 69:227. $48,1980$.

15. GIANNOTTI, J. A. Trabalhe e reflexäo: ensaios para uma dialética da sociabilidade. Sđo Paulo, Brasiliense, 1983.

16. LEFEB VRE, H. A re-prprodução das relaçōes de produção Porto Publicaçōes Escorpião, 1973. 
17. MICHELAT, G. Sobre a utilizaçâo đa entrevista nuีodiretiva em sociologia. In: Thiollent, M. Crítica metodológica, investigaçà sociale enquete operária. Såo Paulo, Polis, 1981. p. 191-211.

18. MINAYO, M. C. de S. O desafio do conhecimento: pesquisa qualitativa em salide. Säo Paulo. HucitecAbrasco, 1992.

19. QUEIROZ, M. I. P. de. Relatos orais: do "indizível" no "dizível". Ciêc. Cuthura, 39 (3):272-86, Ss̃o Paulo, 1987.

20. QUEIROZ, M. I. P. de Variaçóes sobre a técnica de gravador no registro da informação viva. Sâo Paulo, Faculdade de Filosofia, Letras e Ciências Humanas/ USP, 1983. (Textos, $n^{\circ} 4$ ).
21. NUNES, E deO.org. A wentura sociológict-objetividade, paixa, improviso e método na pesquarar social. Rio de Janeiro, Zanhar Ed., 1978.

22. SCHRAIBER, L. B. Medicina liberal e tecrologia: as transformaçōes históricas da autonomia profissional dos médicos em $S$ ão Paulo. Sâo Paulo, Faculdade de Medicina da USP, 1988. [Tese de Doutorado da Faculdade de Medicina da USP].

23. SCHRAIBER, L. B. O médiç e seu trabatho. Limites da liberdade. Să Paulo, Hucitec, 1993.

24. THOMPSON, P. Des récits de vie a I'analjse du changement social. Cah. Int. Sociol., 69:249-68, 1980.

\begin{abstract}
Qualitative research as applied to Public Health and Social Medicine is studied. The project is based upon research into the historical transformation of medical professional autonomy as medicine shifted from the "liberaf" practice to recent "technological" medicine. Field research used unstructured recorded intervie ws to gather perssonal testimonies about the professional histories of physicians who graduated between 1930 and 1955 . These testimonies are technically classiffed as "oral accounts" and were registered as free narratives. This study analysis how accounts can express the physicians'self-representations of their daly work and simultaneousiy write the history of medical practice. Further, the unstructured interview is evaluated as an insirument yielding free narratives and life accounts.
\end{abstract}

Research, methods. Professional practice, history. Social medicine. 